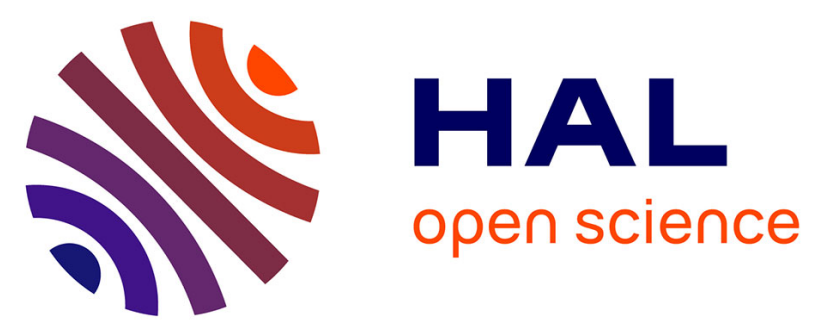

\title{
Review of the AFIS 2018 Academy-Industry meetings in Nancy -The celebration of the 20th anniversary of AFIS!
}

\author{
Eric Levrat, Eric Bonjour, David Gouyon, Pascale Marangé, Frédérique \\ Mayer, Hervé Panetto, Jean-Claude Tucoulou
}

\section{- To cite this version:}

Eric Levrat, Eric Bonjour, David Gouyon, Pascale Marangé, Frédérique Mayer, et al.. Review of the AFIS 2018 Academy-Industry meetings in Nancy -The celebration of the 20th anniversary of AFIS!. INSIGHT - International Council on Systems Engineering (INCOSE), 2019, Systems engineering research at French Universities, 22 (4), pp.9-10. 10.1002/inst.12265 . hal-02423280

\section{HAL Id: hal-02423280 \\ https://hal.science/hal-02423280}

Submitted on 23 Dec 2019

HAL is a multi-disciplinary open access archive for the deposit and dissemination of scientific research documents, whether they are published or not. The documents may come from teaching and research institutions in France or abroad, or from public or private research centers.
L'archive ouverte pluridisciplinaire HAL, est destinée au dépôt et à la diffusion de documents scientifiques de niveau recherche, publiés ou non, émanant des établissements d'enseignement et de recherche français ou étrangers, des laboratoires publics ou privés. 


\title{
Review of the AFIS 2018 Academy-Industry meetings in Nancy - The celebration of the 20th anniversary of AFIS!
}

\author{
Eric Levrat ${ }^{1}$, Eric Bonjour ${ }^{2}$, David Gouyon ${ }^{1}$, Pascale Marangé ${ }^{1}$, Frédérique Mayer ${ }^{2}$, Hervé \\ Panetto $^{1}$, Jean-Claude Tucoulou ${ }^{3}$ (President of the French Chapter of INCOSE, I'AFIS) \\ ${ }^{1}$ Université de Lorraine, CNRS, CRAN, Nancy, France \\ \{eric.levrat, david.gouyon, pascale.marangé, herve.panetto\}@incose.org \\ 2Université de Lorraine, ERPI, Nancy, France \\ \{eric.bonjour, frederique.mayer\}@univ-lorraine.fr \\ AFIS, Pris, France \\ Jean-claude.Tucoulou@afis.fr
}

The AFIS Academy-Industry meetings were organized on 4-6 December 2018 in Nancy at the University of Lorraine. They brought together up to 165 participants in 6 complementary events: the Preforum at the LF2L-ENSGSI, the RobAFIS 2018 competition at the Faculty of Science and Technology, the $8^{\text {th }}$ AFIS Academy-Industry Forum 2018, the Doctoral Seminar 2018, the AFIS Thesis Prize 2018, the celebration of the 20th anniversary of AFIS and the Gala Dinner of the Forum with the theme "AFIS celebrates its 20th anniversary"!

Just a few words about the university that organized these meetings. The University of Lorraine has two pioneering courses, since 2005, in the teaching of Systems Engineering in France and referenced in the "Worldwide directory of systems engineering \& industrial engineering academic programs 2017":

- the Master's Degree in Complex Systems Engineering and

- the National higher School of Engineers in Systems Engineering and Innovation (ENSGSI).

These training courses are supported by research activities mainly carried out on the theme of Systems Engineering in two laboratories of the University of Lorraine: CRAN (Centre de Recherche en Automatique de Nancy, UMR CNRS 7039) and ERPI (Research team on innovative processes).

\section{A very complete agenda}

These meetings provide opportunities for exchanges between academic and industrial communities on the theme of Systems Engineering, its industrial implementation, teaching and related research issues. The unifying theme chosen for this edition was: From the complexity of systems to their acceptance and ease of use. This theme is linked to the expertise, teaching and research in Systems Engineering, developed by the teachers-researchers of the University of Lorraine, organizers of these events. This theme is stated in the form of a paradox, a challenge faced by manufacturers in a context of change from a product economy to a service or even experience economy. How to design systems to control their complexity and ensure simplicity/acceptance of uses? How are Systems Engineering processes and methods impacted by this rationale, how can Systems Engineering facilitate this transition within companies?

Around 5 conferences and 8 workshops led by 20 facilitators (half of them industrialists and academics), the participants discussed about the unifying theme of the forum. In terms of 
participation, we found a good balance between Industry and Academy, which contributes to the Forum's mission to be a place to share and exchange knowledge and practices about SE, in business, education and research.

\section{Acknowledgements}

We would like to thank Paul SCHREINMAKERS, Director of INCOSE's EMEA Sector, for his warm testimony on AFIS' significant contributions to INCOSE's work. This intervention took place in the presence of Jean-Claude ROUSSEL, in charge of the International Relations mission at AFIS and with INCOSE, during the celebration of the 20th anniversary led by Jean-Claude TUCOULOU.

We will also thank the speakers for the high quality of their presentations.

Laurence KUJAWA and Valérie CASTEL (Nexter Group - Nexter Systems). Ergonomics at the heart of user centered design at Nexter Systems.

Catherine DEVIC (EDF). Digital twins for the performance of nuclear power plants... or how to bring models to life.

Christophe DUCAMP (AIRBUS). Virtual simulators and digital twins: how to check \& validate usage as soon as possible.

Damien TRENTESAUX (Deputy Director of GDR MACS - University of Valenciennes). Challenges of civil autonomous systems. Ethics and humanity.

Eric LEVRAT and Eric BONJOUR (University of Lorraine). Complexity of systems and simplicity/acceptance of uses.

Finally, 70 forum participants took the opportunity of the gala dinner to extend these exchanges during another convivial moment.

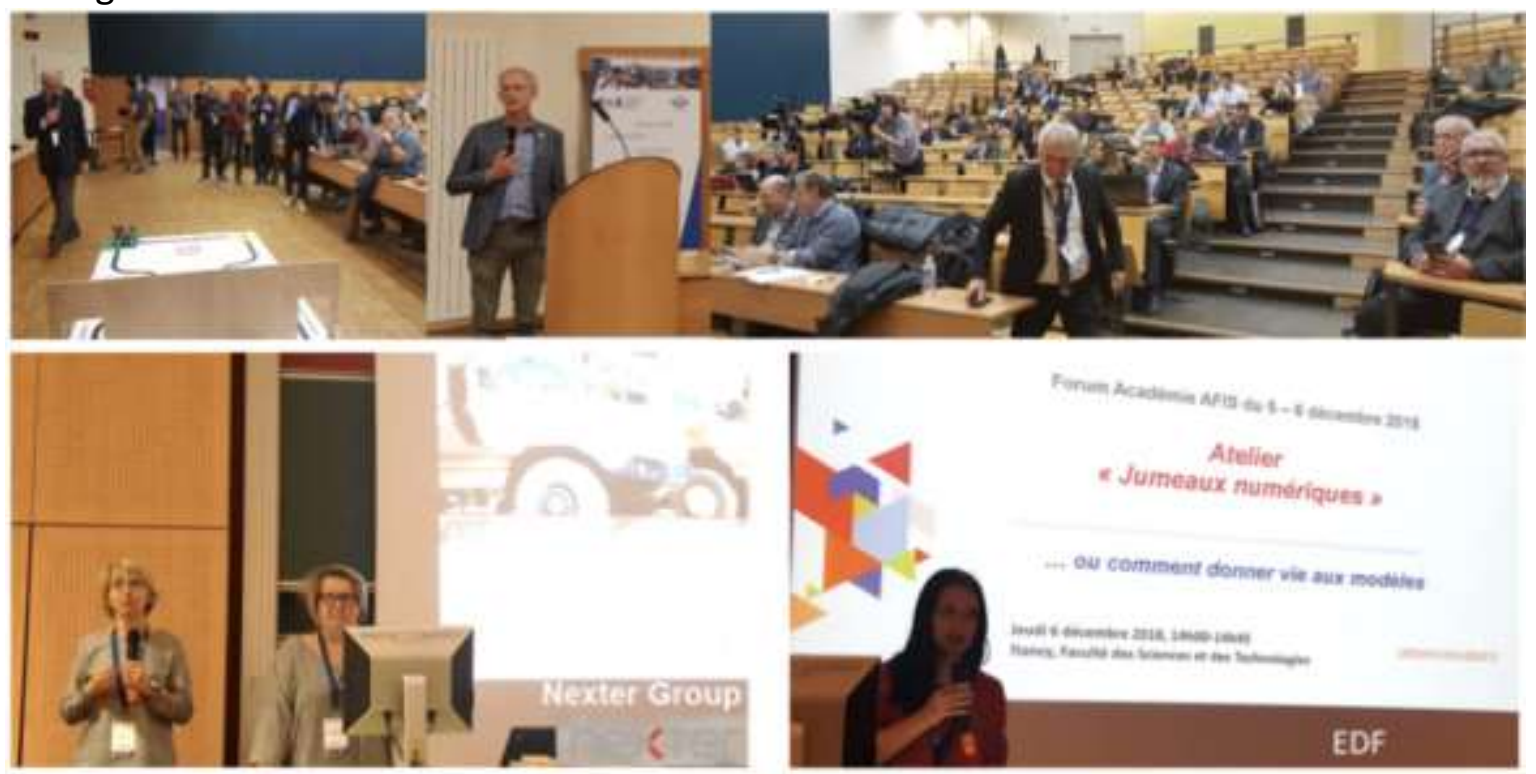


The Preforum is an event organized the day before the forum, with the aim of promoting systems engineering in the region where the forum is located. The theme chosen in 2018 corresponds to a major concern for many SMEs wishing to improve the value of their products and services: Connected objects and innovation: what opportunities and challenges for SMEs?

The AFIS Preforum took place within the Lorraine Fab Living Lab (LF2L ${ }^{\circledR}$ - http://If2I.fr/fr/) which is a co-design platform for the prospective evaluation of uses and the acceptability of innovation developed by the ERPI laboratory in Nancy. It brought together industrialists from SMEs in the Greater East Region, students, lecturers and researchers. But also, industrialists invested within AFIS who came to complete the feedback with their expertise in SE. We would like to thank the speakers who provided very rich feedback and very interesting exchanges with the participants.

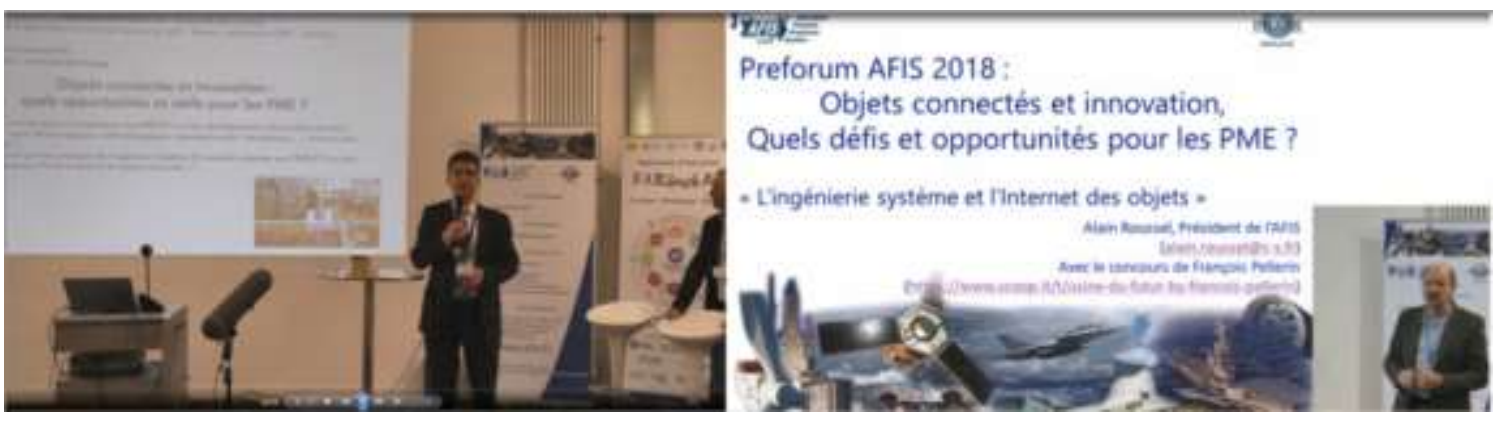

AFIS Prize for the best PhD thesis work in Systems Engineering 2017-2018

For its third edition, the prize for the best PhD thesis work in Systems Engineering 2017-2018, in collaboration with the GIS S-MART, was co-chaired by Frédérique Mayer (University of Lorraine) and Dominique Luzeaux (Habilité à Diriger des Recherches, Ministère des Armées). The results were announced on 6 December 2018, during the AFIS meetings. Eight applications, judged by the jury to be of high quality, were received from doctors who graduated between November 2016 and November 2018. The criteria used for the evaluation were both academic (originality, publications) and industrial (systems approach, impact on SE practices). The winners are as follows. The 2018 winner was Freddy Kamdem Simo, for his thesis work entitled: Model-based federation of systems of modelling. Thesis supervised by Dominique Lenne, UTC, HeuDiaSyc, and Dominique Ernadote, Airbus Defence \& Space. The other winners were Abdourahim Sylla (ENI Tarbes, IMT Mines Albi), Sonia Ben Hamida (CentraleSupelec) and Li Zheng (INSA Toulouse). Congratulations to these winners! 


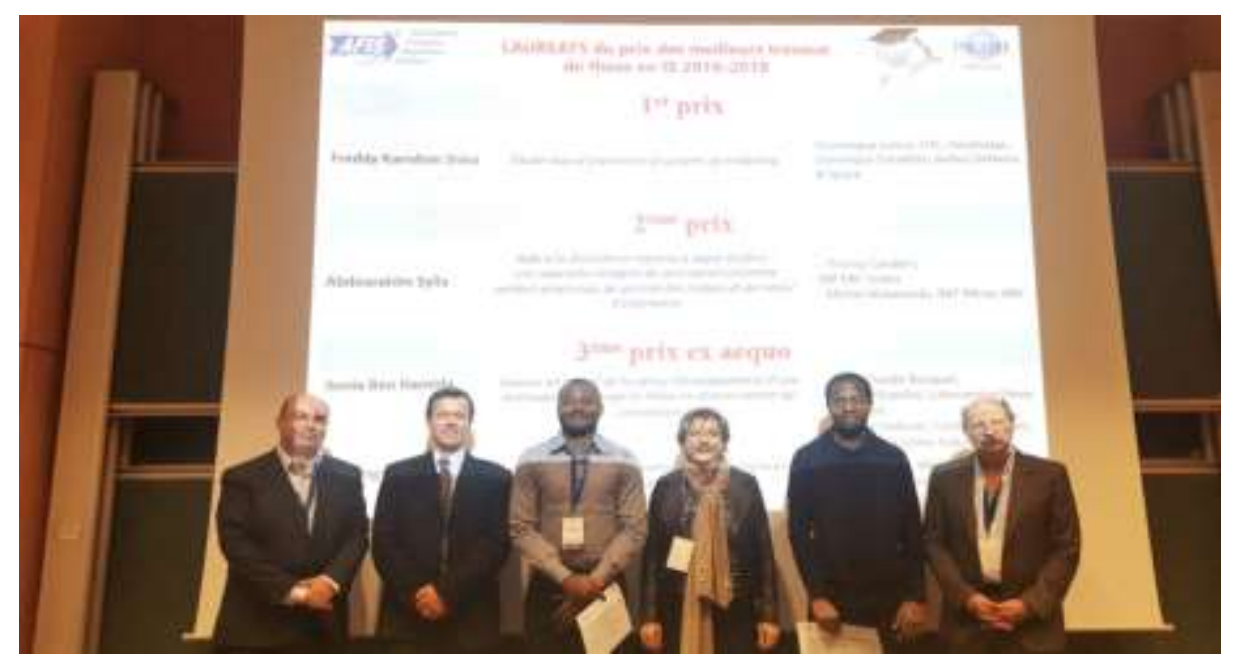

Emmanuel Caillaud (Co-Chair of AFIS), Damien Trentesaux, Abdourahim Sylla, Frédérique Mayer, Freddy Kamdem Simo, Alain Roussel (former president of AFIS)

\section{Doctoral seminar and Best AFIS 2018 Poster Award}

This year, 17 posters were presented for the award for the best AFIS 2018 poster. For AFIS, this is a great success, demonstrating the interest of our Meetings for young researchers and the dynamism of SE research in France. We congratulate the organizers, David Gouyon and Hervé Panetto (University of Lorraine), for the high quality of this event. The 17 participants who submitted a poster were able to take advantage of the free registration for the AFIS 2018 forum. They were thus able to promote their PhD thesis work with the support of their poster and exchange with the participants of the forum.

The 2018 winner of the Best Poster Award is Quentin WU, University of Lorraine, CRAN / SAFRAN Aerosystems. Modeling and reuse of know-how in an MBSE approach: application to aircraft electrical distribution systems.

The participants in the seminar as well as the winners of the PhD thesis prize were invited to write a paper summarizing and enhancing their work. These papers are published in this special issue of INSIGHT.

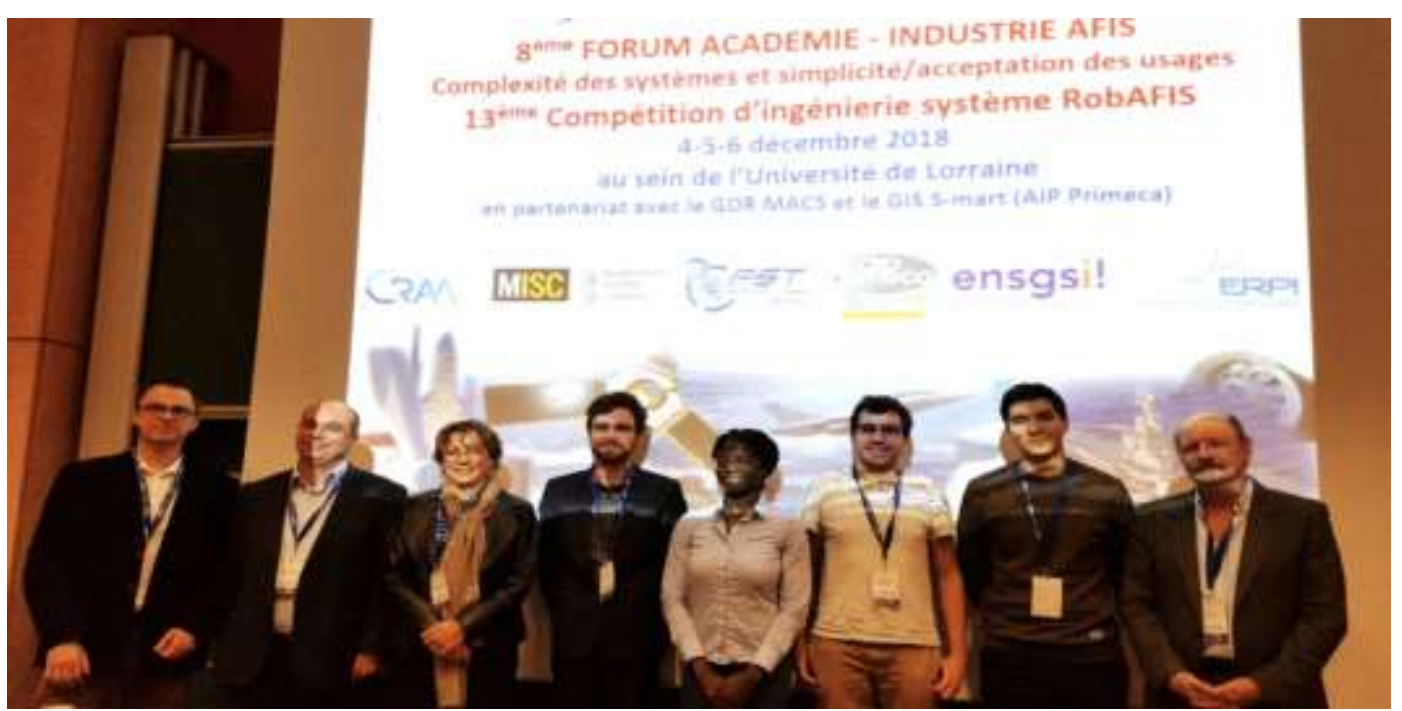

David Gouyon, Emmanuel Caillaud, Frédérique Mayer, Anthony Legendre, Florence Koné, Maxence Lafon, Quentin Wu, Alain Roussel 